\title{
Mixing and chemical ozone loss during and after the Antarctic polar vortex major warming in September 2002
}

\author{
Paul Konopka $^{1}$, Jens-Uwe Grooß ${ }^{1}$, Karl W. Hoppel ${ }^{2}$, \\ Hildegard-Maria Steinhorst ${ }^{1}$ and Rolf Müller ${ }^{1}$ \\ ${ }^{1}$ Institute for Stratospheric Research (ICG I), \\ Research Centre Jülich, Jülich, Germany \\ ${ }^{2}$ Naval Research Lab, Washington DC, USA
}

submitted to J. Atmos. Sci. on 15. 5. 2003;

Version of July 1, 2004

Forschungszentrum J"ulich, Institute for Stratospheric Research (ICG I),

$52425 \mathrm{~J}$ uulich, Germany

(e-mail: p.konopka@fz-juelich.de) 


\section{Abstract}

The 3D version of the Chemical Lagrangian Model of the Stratosphere (CLaMS) was used to study the transport of $\mathrm{CH}_{4}$ and ozone in the Antarctic stratosphere between September 1 and November 30, 2002, i.e. over the time period when unprecedented major stratospheric warming in late September split the polar vortex into two parts. The isentropic and cross-isentropic velocities in CLaMS are derived from ECMWF winds and heating/cooling rates calculated with a radiation module. The irreversible part of transport, i.e. mixing, is driven by the local horizontal strain and vertical shear rates with mixing parameters deduced from in situ observations.

The $\mathrm{CH}_{4}$ distribution after the vortex split shows completely different behavior above and below $600 \mathrm{~K}$. Above this potential temperature level, until the beginning of November, a significant part of vortex air was transported into the midlatitudes up to $40^{\circ} \mathrm{S}$. The lifetime of the vortex remnants formed after the vortex split decreased with altitude with values of about 3 and 6 weeks at 900 and 700 $\mathrm{K}$, respectively.

Despite this enormous dynamical disturbance of the vortex, the intact part between 400 and $600 \mathrm{~K}$ that "survived" the major warming was strongly isolated from the extra-vortex air until the end of November. According to CLaMS simulations, the air masses within this part of the vortex did not experience any significant dilution with the mid-latitude air. 
By transporting ozone in CLaMS as a passive tracer, the chemical ozone loss was estimated from the difference between the observed (POAM III, HALOE) and simulated ozone profiles. Starting from September 1, up to 2.0 ppmv ozone around $480 \mathrm{~K}$ and about $70 \mathrm{DU}$ between 450 and $550 \mathrm{~K}$ was destroyed until the vortex was split. After the major warming, no additional ozone loss can be derived, but in the intact vortex part between 450 and $550 \mathrm{~K}$ the accumulated ozone loss was "frozen in" until the end of November. 


\section{Introduction}

In September 2002, the Antarctic polar vortex was split into two parts due a major stratospheric warming. A major warming had not previously been observed in the period for which data records are available for the Antarctic and it occurred 6 weeks earlier than any final warming observed so far (Charlton et al., 2004; Manney et al., 2004; Newman and Nash, 2004). This unprecedentedly early vortex split created many filaments and vortex remnants containing ozone-depleted air which were rapidly transported into the mid-latitudes (Allen et al., 2003; Orsolini et al., 2004). Transport across the Antarctic vortex edge has been a subject of many studies published in the last 15 years (see e.g. Choi et al. (2002) and references therein).

To study the spatial distribution and the lifetime of the vortex remnants during and after the vortex split in September 2002, high-resolution transport studies of $\mathrm{CH}_{4}$ and passive ozone were carried out with the 3D version of the Chemical Lagrangian Model of the Stratosphere (CLaMS) (Konopka et al., 2004). CLaMS is a chemical transport model that is based on a Lagrangian formulation of tracer transport with mixing intensity being driven by the local horizontal strain and vertical shear rates (McKenna et al., 2002; Konopka et al., 2004).

The parameters controlling the deformation-induced mixing are: the critical Lyapunov exponent $\lambda_{c}$ (that is only flow deformations that are stronger than a certain threshold value, i.e. with the Lyapunov exponents $\lambda$ larger than a critical 
value $\lambda_{c}$, are mixing-relevant), grid adaptation frequency $1 / \Delta t$, and the spatial resolution of the model, i.e. the mean horizontal $r_{0}$ and vertical separation $\Delta z$ between the air parcels (APs). The choice and validation of these parameters is described in detail in (Konopka et al., 2004). Starting from a reliable initialization of the model, CLaMS tracer distributions can be used to quantify the transport of vortex air into the mid-latitudes and, if ozone observations are available, to quantify the chemical ozone loss by comparing the passive ozone transported in the model with the observations (see e.g. Goutail et al., 1999).

In next section, we use $\mathrm{CH}_{4}$ initialized from HALOE observations both to validate the CLaMS transport and to discuss the spatial distribution of the vortex air over the time period covering the split event, i.e. between September 1 and November 30,2002 . In section 3 we quantify how rapidly one part of the vortex was irreversibly mixed into mid-latitude air and how strongly isolated the other part of the vortex was that "survived" the major warming. Furthermore, initializing the model calculations using ozone measurements from both the POAM III (Version 3) (Lucke et al., 1999; Lumpe et al., 2002) and HALOE (Russell et al., 1993) instruments, in section 4 we compare the distribution of passively transported ozone with the measurements from those two satellites available until the end of November. In this way, we study the impact of the major warming on the evolution of the ozone hole. Section 5 discusses the results. 


\section{Tracer transport with CLaMS}

\subsection{Configuration and initialization of the model}

CLaMS transport studies were carried out with Lagrangian APs covering the southern hemisphere in the vertical range between $\theta=350$ and $1400 \mathrm{~K}$, where $\theta$ denotes the potential temperature. The isentropic transport is driven by ECMWF winds, and the cross-isentropic velocities are calculated with a radiation module (Morcrette, 1991; Zhong and Haigh, 1995) and by taking into account profiles of ozone and water vapor derived from a 10 year HALOE climatology.

The mean horizontal separation between the APs, $r_{0}$, is given by $100 \mathrm{~km}$ and $200 \mathrm{~km}$ pole- and equatorward of $30^{\circ} \mathrm{S}$, respectively. The mean vertical separation between the APs results from a prescribed constant aspect ratio $\alpha=250$ that defines the ratio between the horizontal and vertical scales resolved in the model. Thus, the mean vertical separation between the APs is given by 0.4 and $0.8 \mathrm{~km}$ in the high and low resolution regime, respectively. The critical Lyapunov exponent $\lambda_{c}$ is set to 1.5 day $^{-1}$. The grid adaptation frequency is given by $1 / \Delta t$ with the length of the pure advection steps $\Delta t$ set to 24 hours. Konopka et al. (2004) discuss the optimization of these grid and mixing parameters by finding a best agreement between the CLaMS tracer studies and highly resolved in situ observations collected during the SOLVE/THESEO-2000 campaign.

The initial distribution of $\mathrm{CH}_{4}$ and ozone on September 1 is obtained from the results of the Mainz-2D model (Grooß, 1996) combined with HALOE observa- 
tions between August 11 and September 10 which are used to correct the distributions from the Mainz-2D model in the mid-latitudes and in the vortex. The details of the isentropic version of the initialization are described by Grooß et al. (2004) (see Fig. 1). Here, we generalize this procedure to 15 isentropic levels uniformly covering the vertical domain of the model and interpolate between these levels to initialize the Lagrangian APs with vertical positions in between. The initial distribution of ozone in the vortex is further adjusted employing POAM III observation by maximizing the correlation coefficient between the observed and transported ozone values during the first 6 days of simulation.

To quantify the dilution of the vortex air due to intrusions of the mid-latitude air into the vortex, an artificial tracer is transported in ClaMS that marks at the begin of the simulation, on September 1, the APs inside and outside the vortex as $100 \%$ and $0 \%$, respectively, with the vortex edge defined by the maximum PV gradient (Nash et al., 1996). This vortex tracer describes the percentage of pure vortex air in each AP over the course of the model run. The boundary conditions at the top and bottom layers are applied after each time step $\Delta t$ and are derived from the $\mathrm{PV} / \mathrm{CH}_{4}$ and $\mathrm{CH}_{4} /$ ozone correlations valid in these layers at the initialization time. The boundary conditions for the artificial vortex tracer are defined, as at the initialization time, by using the Nash criterion. 


\subsection{CLaMS $\mathrm{CH}_{4}$ distributions during the split event}

The model results for $\mathrm{CLaMS}_{4}$ distribution for September 21 (i.e. before the vortex split), for September 26 (i.e. during the vortex split) and for October 20 (i.e. after the vortex split) are shown in the first, second and third columns of Fig. 1, respectively. In particular, the isentropic distribution of $\mathrm{CH}_{4}$ at $\theta=500$ and $800 \mathrm{~K}$ can be seen in the first two rows of Fig. 1 (the white solid lines denote the vortex edge). The third row shows the vertical cross section along the $55^{\circ} \mathrm{E}$ $\left(-125^{\circ} \mathrm{W}\right)$ meridian that corresponds to the white dashed lines in the first two rows of Fig. 1. In the last two rows, the contours of the vortex edge derived from the CLaMS distribution of $\mathrm{CH}_{4}$ and from the ECMWF-PV fields with the spatial resolution $1.125^{\circ}(\mathrm{T} 106)$ by using the Nash et al. (1996) criterion are shown and colored corresponding to their potential temperature levels. The vortex edge in the $\mathrm{CH}_{4}$ distribution is defined in the same way as for the PV fields, i.e. by the strongest gradient of $\mathrm{CH}_{4}$ with respect to the equivalent latitude at the potential temperature level considered.

In contrast to the vortex edge derived from a purely dynamical quantity such as $\mathrm{PV}$, the edge contours in the $\mathrm{CH}_{4}$ distribution show many small-scale structures, in particular during and after the periods when planetary wave activity created several pronounced filaments in the vicinity of the vortex edge. To some extent this difference may be caused by the coarse spatial resolution of the PV fields used (T106). As discussed in Simmons et al. (2004) and Orsolini et al. (2004), a higher variability of PV fields can be derived from the very-high-resolution ECMWF 
analysis with a spatial resolution of about $0.2^{\circ}$ (T511). Nevertheless, during this dynamically active period, a weak $\mathrm{PV} / \mathrm{CH}_{4}$ has to be expected for air masses originating in the vortex (Tuck et al., 1997).

On September 21, i.e. a few days prior to the split, the vortex was still compact at both the 500 and $800 \mathrm{~K}$ level even if a deviation from the circumpolar position and a meridional elongation indicate that planetary waves with zonal wave numbers 1 and 2 strongly disturbed its dynamics. Despite a small filament of vortex air near New Zealand the vortex was still intact. Its compactness can be seen both in the vertical cross section and in negligible differences between the position of the vortex edge derived from the analyzed ECMWF PV fields and from the CLaMS $\mathrm{CH}_{4}$ distribution (see last two rows of Fig. 1).

During the following days, the combined impact of the planetary waves 1 and 2 resulted in the first ever observed major stratospheric warming in the southern hemisphere (Newman and Nash, 2004) that split the vortex into two parts. This vortex breakdown was a top-down process, i.e. the wind reversal occurred earlier at higher altitudes (Orsolini et al., 2004). In particular, two distinct centers can be seen on September 26 at $\theta=800 \mathrm{~K}$. The region between these two centers is characterized by very high Lyapunov exponents (not shown) indicating enormous horizontal and vertical deformation rates which, owing to the CLaMS mixing algorithm, are accompanied by strong mixing between the neighboring APs in the model (Konopka et al., 2004). The dashed blue lines in the vertical cross section (Fig. 1, row 3) show schematically the boomerang-like shape of the vortex with 
the characteristic two arms (lobes) above $\theta \approx 650 \mathrm{~K}$, which are slanted by the vertical shear of the zonal wind (note that a vertical cross section cannot completely show these two slanted lobes). This boomerang-like shape of the vortex can also be recognized in the contour plots of the vortex edge derived from the $\mathrm{CH}_{4}$ and PV fields (Fig. 1, rows 4 and 5). Here, in addition to the vortex edge derived from the analyzed PV, some filaments and vortex remnants are present in the contours derived from the $\mathrm{CH}_{4}$ distribution.

In the subsequent 5 days (not shown), the vortex arm above South America became smaller, zonally stretched and vertically sheared and, consequently, broke up in many fragments which were transported equatorwards. The vortex arm near southern Africa returned to the pole and, together with the only slightly disturbed vortex part between 400 and $650 \mathrm{~K}$, re-established a circumpolar vortex. This remerged vortex, however, is characterized by much smaller zonal winds and a much smaller area than before the split event.

The spatial distribution of $\mathrm{CH}_{4}$ about 3 weeks later, on October 20, can be seen both in the right-hand column of Fig. 1 and in Fig. 2 where zonally averaged (i.e. in the equivalent latitude space) values of $\mathrm{CH}_{4}$ are shown. The colors within the circles on the isentropic cross section in Fig. 1 (row 1 and 2) denote the HALOE measurements (mapped to 12 UTC), which agree fairly well with the CLaMS calculations. A clear signature of the diabatic descent in the vortex during the vortex split can be seen on October 20 at $\theta=500 \mathrm{~K}$ by comparing the $\mathrm{CH}_{4}$ distribution on this day with the corresponding distribution on September 26. The 
strongest descent rates are simulated near the vortex edge with the total descent near the edge exceeding the subsidence of the vortex core by about $15 \mathrm{~K}$ (see also Fig. 2).

The vertical cross section of the $\mathrm{CH}_{4}$ distribution on October 20 (see Fig. 1, row 3) shows clear signatures of vortex remnants in the altitude region between 600 and $1000 \mathrm{~K}$. In particular, the vortex edge contours derived from $\mathrm{CH}_{4}$ fields have more small-scale structures if compared with the vortex edge derived from the analyzed ECMWF PV. This indicates that the stratospheric dynamics, triggered by the vortex split, creates tracer fields with much higher spatial variability than the analyzed PV fields can resolve.

Furthermore, the zonally averaged $\mathrm{CH}_{4}$ distribution shown in Fig. 2 together with the contour lines (black lines) of the zonally averaged vortex tracer indicate that, despite the strong distortion of the Antarctic stratosphere caused by the split event, the lower part of the vortex below about $600 \mathrm{~K}$ remained well isolated from the influence of mid-latitude air masses. The white dots denoting the equivalent latitude of the vortex edge agree fairly well with the $75 \%$ contour line of the vortex tracer. Thus, the region between the $75 \%$ and $98 \%$ contour lines can be interpreted as the mixing zone inside the vortex in the vicinity of the vortex edge. The air masses with a percentage of $98 \%$ and greater constitute the practically unmixed core of the vortex. 


\subsection{CLaMS $\mathrm{CH}_{4}$ versus HALOE observations}

Before discussing the spatial distribution and the lifetime of the vortex remnants, in Fig. 3 we investigate the quality of CLaMS transport by studying the correlation between HALOE observations of $\mathrm{CH}_{4}$ from September 1 to November 30 poleward of $30^{\circ} \mathrm{S}$ and the corresponding CLaMS simulations. The colors denote the percentage of pure vortex air within the simulated air masses. In the top panel of Fig. 3, the nearest CLaMS APs relative to the HALOE observation (tangent point) are used. By applying this method, a good correlation between CLaMS simulation and HALOE observation could be achieved before the vortex split (filled circles) whereas after the split (open triangles) some deviations are present for air masses containing vortex air (gray shaded area). Such air masses with a large percentage of pure vortex air were sampled near the vortex edge and can be assigned, within the model, to some small-scale vortex remnants formed after the split event. Many of these features are below the spatial resolution of the HALOE instrument where the horizontal and vertical scales of the sampled volume are of the order of 500 $\mathrm{km}$ and $4 \mathrm{~km}$, respectively (Russell et al., 1993).

In the bottom panel of Fig. 3 a weighted interpolation is used that mimics the HALOE observation geometry. In particular, we represent the sampled HALOE volume (cylinder) by 3 colinear points separated by $250 \mathrm{~km}$, map these points to the synoptic time, and determine the nearest CLaMS AP to each of these points. The mean value over these 3 CLaMS APs now represents one HALOE measurement with the consequence that the correlation coefficient increases from 0.85 for 
the nearest neighbor approximation (top panel) to 0.92 for the weighted interpolation (bottom panel). The remaining deviations are probably caused by the errors of the simulated absolute position of the vortex remnants.

\section{Spatial distribution and lifetime of vortex rem- nants}

The investigation of the $\mathrm{CH}_{4}$ distributions as discussed in the previous section has shown that, after the split event, the lower stratospheric vortex remained intact while the large part of the middle stratospheric vortex was rapidly redistributed over the southern hemisphere. By analyzing the (artificial) vortex tracer we now study the impact of the major warming on the dilution of the air masses in the vortex and on the meridional redistribution of the air masses originating from the vortex. Furthermore, we investigate the influence of the stratospheric mixing on the lifetime of vortex remnants formed during the major warming when a significant part of the vortex above $600 \mathrm{~K}$ decayed into many small fragments.

The zonally averaged meridional distribution of the vortex air calculated as a function of time and equivalent latitude at two isentropic levels $\theta=500$ and $800 \mathrm{~K}$ is shown in Fig. 4. In this figure, a high percentage of vortex air (logarithmic color scale!) means that only a small fraction of the APs in a bin around the equivalent latitude considered originates from the extra vortex region defined at the initialization time. The white contours denote the zonally averaged (i.e. averaged in the equivalent latitude space) wind speed (in $\mathrm{m} / \mathrm{s}$ ) and the gray line is the equivalent 
latitude of the vortex edge derived from the Nash et al. (1996) criterion.

By comparing the top and bottom panels in Fig. 4, clear differences in the meridional distributions of the vortex air at $\theta=800$ and $500 \mathrm{~K}$ can be seen. Whereas at $\theta=800 \mathrm{~K}$, after September 26, a rapid erosion of the vortex coupled with a fast redistribution of the vortex air masses over the mid-latitudes can be observed (up to $40^{\circ} \mathrm{S}$ ), the impact of the major warming on the distribution of vortex air at $\theta=500 \mathrm{~K}$ is more moderate. At both the 500 and $800 \mathrm{~K}$ level, the vortex edge shrinks in early October to equivalent latitude values of about $78^{\circ}$ and $68^{\circ} \mathrm{S}$, respectively, and correlates fairly well with high wind velocities at the poleward flanks of the jet stream. The vortex at $500 \mathrm{~K}$ prevails until the end of November with a high percentage of the vortex air in the equivalent latitude range between $85^{\circ}$ and $90^{\circ} \mathrm{S}$. At $800 \mathrm{~K}$, although the Nash criterion indicates a recovery of the vortex at $800 \mathrm{~K}$ level after the final warming around October 25 , the stratospheric winds are not strong enough to justify this conclusion. This statement is further corroborated by a strong dilution of the vortex tracer after this date. The fact that, under certain circumstances, the vortex edge defined by the Nash criterion does not constitute a strong transport barrier has recently been reported for the Arctic vortex by Steinhorst et al. (2004).

It should be emphasized that mixing, that is the irreversible part of transport, has a negligible influence on the discussed meridional distribution of the vortex air. Even for CLaMS simulations without mixing (pure trajectory calculations, not shown), the zonal averaging of the (unmixed) air parcels leads to a similar 
meridional distribution of the vortex air as for a simulation where mixing would be exaggerated (for a detailed study of this effect see Konopka et al. (2003)). Thus, the large-scale meridional transport of vortex air into the mid-latitudes is controlled by the chaotic advection induced by planetary waves rather than by mixing.

However, mixing may significantly influence the lifetime of vortex remnants, i.e., the time that is necessary to mix vortex air homogeneously with ambient air (Konopka et al., 2003). To quantify this effect, we define an AP as only weakly mixed or clearly distinguished from the extra vortex air, if the percentage of pure vortex air in such air masses is greater than 75\%. By analyzing CLaMS simulations with optimized mixing parameters, we calculate in each isentropic layer the relative contribution of such "unmixed" APs to all APs in the layer southward of $30^{\circ} \mathrm{S}$. The results of this procedure are shown in Fig. 5. It should be emphasized that, in contrast to the meridional distribution of the vortex air discussed in Fig. 4, this kind of diagnostics is strongly sensitive to the intensity of mixing in the model.

To quantify the lifetime of the vortex remnants, we define the vortex air in the remnants as homogeneously mixed with the mid-latitude air, if the relative contribution of the weakly mixed APs in the considered isentropic level poleward of $30^{\circ} \mathrm{S}$ is less than $1 \%$ (gray dashed line in Fig. 5). About 3 weeks after the split, a strong homogenization of vortex remnants occurs in the altitude region $850-1000$ $\mathrm{K}$. The lifetime of the remnants increases with decreasing altitude up to about 6 
weeks around $700 \mathrm{~K}$. In the altitude range between 400 and $600 \mathrm{~K}$ an intact vortex explains the large relative contribution of strongly isolated vortex air masses. The inferred lifetime of the vortex remnants increases (decreases) by about $10 \%$ if the threshold value defining the weakly mixed vortex air is changed from $75 \%$ to $65 \%$ $(85 \%)$.

\section{Ozone loss}

Using profiles of ozone measured by the POAM III satellite instrument, Hoppel et al. (2003) showed that although the 2002 Antarctic ozone loss was similar to previous years up to the time of the major warming, the intensity of the ozone loss was strongly diminished after the major warming resulting in up to $20 \%$ less chemical ozone loss in the total column within the vortex than in previous winters. Furthermore, based on the very low ozone mixing ratios within the vortex core at $500 \mathrm{~K}$ observed by POAM III in October and November, they suggested that the smaller vortex that re-established after the split event was largely isolated. Using the 2D version of CLaMS with full chemistry, Grooß et al. (2004) have shown that the increase of the polar temperatures during the late September major warming was strong enough to lead to the disappearance of PSCs, resulting in a very rapid deactivation of active chlorine under these conditions and thus to a stop of the chemical ozone loss within the vortex.

By comparing the CLaMS passive ozone with the POAM III and HALOE ozone observations, we now investigate the chemical ozone loss in the vortex 
since September 1 and, subsequently, in the part that "survived" the split event around September 26. The calculated mean ozone loss in the vortex is shown in Fig. 6. Here the mean difference between POAM III ozone observation and the corresponding CLaMS results for the passive ozone tracer is calculated for a given potential temperature level and averaged over a 5-day period around the day under consideration (running mean). Only days when more than five POAM III ozone profiles are available were considered. The gray line in Fig. 6, top panel, is the $8 \%$ contour of the distribution shown in Fig. 5 defining the region with pure, wellisolated vortex air. The white region above $500 \mathrm{~K}$ and around the split date is due to the non-circumpolar position of the vortex so that vortex air was not sampled by the POAM instrument. In the bottom panel of Fig. 6, the column ozone loss integrated between 425 and $575 \mathrm{~K}$ is shown (dashed gray lines in the top panel of Fig. 6). A similar analysis based on HALOE ozone observation was carried out for two periods around October 20 and November 10 when HALOE sampled the interior of the vortex. The results (green points in the lower panel of Fig. 6) confirm rather well the ozone loss derived from POAM measurements.

According to this analysis, a strong ozone loss up to 2 ppmv locally and $70 \mathrm{DU}$ between 425 and $575 \mathrm{~K}$ occurred in the 2 weeks before the vortex split. A strong increase of the column ozone loss shortly before the split, then a decrease in early October and, finally, a slow increase up to the end of November anticorrelates with the fluctuations in the pressure range in which the column ozone loss was calculated, (this pressure range corresponds to $425-575 \mathrm{~K}$ potential temperature 
range, see gray stripe in the bottom panel of Fig. 6). The variations of this range are triggered by the temperature fluctuations caused by the split, i.e. by strong warming and cooling before and after the split date (black line) and subsequent slow warming until the end of November. Thus, these diabatic effects rather than chemical processes are responsible for the calculated fluctuations of the column ozone loss after the vortex split. This indicates that, from the end of September until the end of November, the ozone loss is "frozen in" in the well-isolated part of the vortex below $550 \mathrm{~K}$ after the warming ended.

A slightly different way of presenting these results is shown in Fig. 7. Here the $\mathrm{CH}_{4}$ /ozone correlations based on POAM III ozone observations in the vortex within the altitude range $400-600 \mathrm{~K}$ (crosses, $\mathrm{CH}_{4}$ values are derived from the CLaMS simulations) are compared with the corresponding CLaMS simulations of passive ozone (circles) for 3 time periods after the vortex split: 5-11, 15-21 October and 20-30 November. The colors denote the potential temperature (left column) and the percentage of pure vortex air (right column).

As in the TRAC method for deducing chemical ozone loss (see e.g. Müller et al., 1996; Tilmes et al., 2003), the $\mathrm{CH}_{4}$ correlation with passive ozone can be considered as a reference, compared to which the chemical ozone loss becomes obvious as a deviation from the observed $\mathrm{CH}_{4}$ /ozone correlation from this reference. Thus, the strong deviation between the passive ozone reference and the $\mathrm{CH}_{4}$ /ozone relation based on POAM III ozone measurements (marked by the gray region) is a measure of chemical ozone loss. The compactness of the 
$\mathrm{CH}_{4}$ /ozone correlations did not significantly change in the time between the split in late September and the end of October indicating a strong isolation of the considered air masses. Some signatures of mixing can be seen after November 20 (bottom panels of Fig. 7) although the compactness of the $\mathrm{CH}_{4} /$ ozone correlations is still well defined. In particular, some air masses characterized by a low fraction of vortex air (right column, bottom panel in Fig. 7) show a clear deviation (towards higher ozone values) from the compact $\mathrm{CH}_{4} /$ ozone correlation. Note that the increase of the highest ozone values during that time period (top to bottom in Fig. 7) is due to continuing diabatic descent in the vortex.

Thus, we conclude that the chemical loss did not change significantly after the split which means that further chemical loss did not occurr nor was the signature of the chemical loss destroyed by mixing. The inferred ozone loss is mainly found in well-isolated vortex air masses (see red symbols in Fig. 7, right column), with the highest values of up to 2 ppmv loss in the altitude range 450 and $550 \mathrm{~K}$ occurring between September 1 (initialization) and the end of October.

\section{Discussion}

During the fall of 2002, the Antarctic polar vortex experienced an unusually strong disturbance at the end of September because of the major stratospheric warming that resulted in a split of the vortex into two parts. By carrying out high resolution, 3D simulations with the Chemical Lagrangian Model of the Stratosphere (CLaMS), both the split process itself and the subsequent redistribution of the 
vortex air were considered.

In previous studies considering the details of the transport of the vortex air into the mid-latitudes, Hess (1991) found in the LIMS data (LIMS - Limb Infrared Monitor of the Stratosphere) and GCM simulations that long-lived anomalies of tracers were still observed two months after the breakup of the polar vortex in spring 1979. Using the probability density function (PDF) technique for 3D simulations of $\mathrm{N}_{2} \mathrm{O}$, Orsolini (2001) identified some long-lived westward-propagating tracer patterns in the 1998 boreal summer polar stratosphere above $20 \mathrm{~km}$ that resulted from the slow advection of partly mixed vortex remnants. By analyzing isentropic CLaMS-2D tracer distributions over the entire northern hemisphere during late spring and early summer 1997, Konopka et al. (2003) have shown that significant differences exist in the distribution and in the lifetime of the vortex remnants formed after the Arctic vortex breakup in May 1997 above and below $20 \mathrm{~km}$. Above $20 \mathrm{~km}$, vortex remnants effectively propagate southward (up to $40^{\circ} \mathrm{N}$ ) and are "frozen" in the summer circulation without significant mixing. Below $20 \mathrm{~km}$, their lifetime is shorter by a factor of 2 owing to significant stirring below this altitude.

The analysis of the mixing processes after the split event in September 2002 together with studies of the breakup of the Artic vortex in spring 2000 (Konopka et al., 2003) allows the following picture to be developed of transport processes governing the lifetime of the vortex remnants. A long lifetime of the remnants correlates with high absolute PV values within such air masses indicating that 
strong rotation or high angular momentum prevents dispersion of the APs within the remnants (McWilliams, 1984) and, consequently, mixing between such air masses and mid-latitude air, at least in CLaMS, is limited. (In CLaMS, if the relative distances of the APs to their neighbors does not significantly change during transport, i.e. the grid of the neighboring APs is not deformed so that, owing to the mixing algorithm, such APs do not mix (Konopka et al., 2004).) After the potential vorticity of the remnants has dissipated due to diabatic processes or due to friction, mixing of the APs belonging to such air masses is no longer constrained by a PV barrier and, depending on the deformations in the "ambient" flow, can disperse and, finally, be mixed. Of course, this subsequent transport process depends on the intensity of the horizontal (strain) and vertical (shear) deformations in the flow. E.g., the solid body rotation in the summer stratosphere above $20 \mathrm{~km}$ mixes much more weakly than the strong or moderate activity of planetary waves, usually present in the stratosphere after a breakup of the polar vortices (Konopka et al., 2003).

By comparing the CLaMS and POAM III/HALOE $\mathrm{CH}_{4} /$ ozone correlations between September 1 and the end of November, a clear signature of ozone loss can be seen in the part of the vortex that "survived" the major warming in September 2002, i.e. between 400 and 600 K. Despite this strong dynamical disturbance of the stratosphere, these air masses consisted of almost pure vortex air indicating negligible dilution with air coming from mid-latitudes. In these well-isolated air masses up to 2.0 ppmv of ozone was depleted during the period under consider- 
ation with the highest absolute values around 480 K. Starting from September 1, about 70 DU of ozone was destroyed up to the vortex split around September 25. After this date the accumulated ozone loss was "frozen in" the vortex core and transported until the end of November without no further chemical loss nor any significant dilution by transport across the vortex edge. According to the sensitivity studies with backward trajectories, these results are not influenced by the boundary condition used in CLaMS simulations. Furthermore, isentropic studies with full chemistry (Grooß, 1996) and 3D investigations with linearized ozone chemistry (Sinnhuber et al., 2003) support our conclusion that the vortex split stopped the chemical ozone loss.

\section{Acknowledgments}

The European Centre for Medium-Range Weather Forecasts (ECMWF) is acknowledged for meteorological data support. We thank Yvan Orsolini and two anonymous reviewers for their constructive remarks. 


\section{References}

Allen, D., R. Bevilacqua, G. Nedoluha, C. Randall and G. Manney, 2003: Unusual stratospheric transport and mixing during the 2002 Antarctic winter. Geophys. Res. Lett., 30(12), 1599, doi:10.1029/2003GL017117.

Charlton, A. J., A. O'Neill, W. A. Lahoz and P. Berrisford, 2004: The splitting of the stratospheric polar vortex in the southern hemisphere, September 2002: Dynamical evolution. J. Atmos. Sci., submitted.

Choi, W., S. Kim, W. B. Grant, M. Shiotani, Y. Sasano and M. R. Schoeberl, 2002: Transport of methane in the stratosphere associated with the breakdown of the Antarctic polar vortex. J. Geophys. Res., 107, 8209, doi:10.1029/2001JD000644.

Goutail, F., J.-P. Pommereau, C. Phillips, C. Deniel, A. Sarkssian, F. Lefèvre, E. Kyrö, M. Rummukainen, P. Ericksen, S. B. Andersen, B.-A. KaastadHoiskar, G. Braathen, V. Dorokhov and V. U. Khattatov, 1999: Depletion of column ozone in the Arctic during the winter of 1993-94 and 1994-95. J Atmos Chem, 32, 1-34.

Grooß, J.-U., 1996: Modelling of Stratospheric Chemistry based on HALOE/UARS Satellite Data. PhD thesis, University of Mainz.

Grooß, J.-U., P. Konopka and R. Müller, 2004: Ozone chemistry during the 2002 Antarctic vortex split. J. Atmos. Sci., submitted. 
Hess, P., 1991: Mixing processes following the final stratospheric warming. $J$. Atmos. Sci., 42, 1625-1641.

Hoppel, K., R. Bevilacqua, D. Allen, G. Nedoluha and C. Randall, 2003: POAM III Observations of the anomalous 2002 Antarctic ozone hole. Geophys. Res. Lett., 30, 1394, doi:10.1029/2002GL016899.

Konopka, P., J.-U. Grooß, S. Bausch, R. Müller, D. S. McKenna, O. Morgenstern and Y. Orsolini, 2003: Dynamics and chemistry of vortex remnants in late Arctic spring 1997 and 2000: Simulations with the Chemical Lagrangian Model of the Stratosphere (CLaMS). Atmos. Chem. Phys., 3, 839-849.

Konopka, P., H.-M. Steinhorst, J.-U. Grooß, G. Günther, R. Müller, J. W. Elkins, H.-J. Jost, E. Richard, U. Schmidt, G. Toon and D. S. McKenna, 2004: Mixing and ozone loss in the 1999-2000 arctic vortex: Simulations with the 3dimensional Chemical Lagrangian Model of the Stratosphere (CLaMS). J. Geophys. Res., 109(D2), doi:10.1029/2003JD003792.

Lucke, R. L., D. R. Korwan, R. M. Bevilacqua, J. S. Hornstein, E. P. Shettle, D. T. Chen, M. Daehler, J. D. Lumpe, M. D. Fromm, D. Debrestian, B. Neff, M. Squire, G. König-Langlo and J. Davies, 1999: The Polar Ozone and Aerosol Measurement (POAM) III instrument and early validation results. J. Geophys. Res., 104, 18785-18799.

Lumpe, J. D., R. M. Bevilacqua, K. W. Hoppel and C. E. Randell, 2002: 
POAM III retrieval algorithm and error analysis. J. Geophys. Res., 107(D21), doi:10.1029/2002JD002137.

Manney, G. L., J. L. Sabitus, D. R. Allen, W. A. Lahoz, A. A. Scaife, C. E. Randell, S. Pawson, B. Naujokat and R. Swinbank, 2004: Simulations of dynamics and transport during the September 2002 Antarctic major warming. J. Atmos. Sci., submitted.

McKenna, D. S., P. Konopka, J.-U. Grooß, G. Günther, R. Müller, R. Spang, D. Offermann and Y. Orsolini, 2002: A new Chemical Lagrangian Model of the Stratosphere (CLaMS): Part I Formulation of advection and mixing. J. Geophys. Res., 107(D16), 4309, doi:10.1029/2000JD000114.

McWilliams, J. C., 1984: The emergency of isolated coherent vortices in turbulent flow. J Fluid Mech, 146, 21-34.

Morcrette, J.-J., 1991: Radiation and cloud radiative properties in the European Centre for Medium-Range Weather Forecasts forecasting system. J. Geophys. Res., 96(D5), 9121-9132.

Müller, R., P. J. Crutzen, J.-U. Grooß, C. Brühl, J. M. Russel III and A. F. Tuck, 1996: Chlorine activation and ozone depletion in the Arctic vortex: Observations by the Halogen Occultation Experiment on the Upper Atmosphere Research Satellite. J. Geophys. Res., 101, 12531-12554.

Nash, E. R., P. A. Newman, J. E. Rosenfield and M. R. Schoeberl, 1996: An 
objective determination of the polar vortex using Ertel's potential vorticity. $J$. Geophys. Res., 101, 9471-9478.

Newman, P. and E. Nash, 2004: The unusual southern hemisphere stratosphere winter of 2002. J Atmos Sci, submitted.

Orsolini, Y. J., 2001: Long-lived tracer patterns in the summer polar stratosphere. Geophys. Res. Lett., 28, 3855-3858.

Orsolini, Y. J., C. Randall, M. G. and D. R. Allen, 2004: An observational study of the final breakdown of the southern hemisphere stratospheric vortex in 2002. J Atmos Sci, submitted.

Russell, J. M., L. L. Gordley, J. H. Park, S. R. Drayson, A. F. Tuck, J. E. Harries, R. J. Cicerone, P. J. Crutzen and J. E. Frederick, 1993: The Halogen Occultation Experiment. J. Geophys. Res., 98, 10777-10797.

Simmons, A., M. Hortal, G. Kelly, A. McNally, A. Untch and S. Uppala, 2004: ECMWF analyses and forecasts of stratospheric winter polar vortex break-up: September 2002 in the southern hemisphere and related events. J. Atmos. Sci., submitted.

Sinnhuber, B.-M., M. Weber, A. Amankwah and J. P. Burrows, 2003: Total ozone during the unusual Antarctic winter of 2002. Geophys. Res. Lett., 30, 1580, doi:10.1029/2002GL016798. 
Steinhorst, H.-M., P. Konopka, G. Günther and R. Müller, 2004: How permeable is the edge of the Arctic vortex - Model studies of the winter 1999-2000. J. Geophys. Res., submitted.

Tilmes, S., R. Müller, J.-U. Grooß, M. Höpfner, G. C. Toon and J. M. I. Russell, 2003: Very early chlorine activation and ozone loss in the arctic winter 20022003. Geophys. Res. Lett., 30(23), 2201.

Tuck, A. F., D. Baumgardner, K. R. Chan, J. E. Dye, J. W. Elkins, S. J. Hovde, K. K. Kelly, M. Loewenstein, J. J. Margitan, R. D. May, J. R. Podolske, M. H. Proffitt, K. H. Rosenlof, W. L. Smith, C. R. Webster and J. C. Wilson, 1997: The Brewer-Dobson circulation in the light of high altitude in situ aircraft observation. Q J R Meteorol Soc, 123, 1-69.

Zhong, W. and J. D. Haigh, 1995: Improved broadband emissivity parameterization for water vapor cooling rate calculations. J. Atmos. Sci., 52(1), 124-138. 


\section{Figure Captions}

Fig. 1: CLaMS distribution of $\mathrm{CH}_{4}$ on September 21 (left column) September 26 (middle column) and October 20 (right column). In the first two rows the isentropic cross sections at $\theta=500$ and $800 \mathrm{~K}$ are plotted (colors within the circles denote the HALOE observations). The third row shows the vertical cross sections along the $55^{\circ} \mathrm{E}\left(-125^{\circ} \mathrm{W}\right)$ meridian that corresponds to the white dashed lines in the first two rows. The last two rows show the contours of the vortex edge colored with its potential temperature and derived from the strongest gradients of ECMWF-PV (fourth row) or $\mathrm{CH}_{4}$ (last row) with respect to the equivalent latitude, i.e. according to the procedure described by Nash et al. (1996).

Fig. 2: Zonally averaged (i.e. in the equivalent latitude space) vertical cross section of CLaMS $\mathrm{CH}_{4}$ distribution calculated on October 20. The black lines are the contours of the zonally averaged vortex tracer confining air masses with $75 \%$ and $98 \%$ percentage of pure vortex air, respectively. The white points denote the vortex edge after Nash et al. (1996).

Fig. 3: Correlation plot between the HALOE observations from September 1 to November 30 and the corresponding CLaMS-3d results calculated for two method of interpolation: nearest neighbor approximation (top panel) and weighted interpolation (bottom panel). The colors denote percentages of the pure vortex air in the air masses considered. The gray triangles underlie points traceable to weakly diluted vortex remnants. 
Fig. 4: Percentage of vortex air at $\theta=800 \mathrm{~K}$ (top) and $\theta=500 \mathrm{~K}$ (bottom) plotted as a function of time and of the equivalent latitude. The white contours denote the zonally averaged (i.e. in the equivalent latitude space) horizontal wind (in $\mathrm{m} / \mathrm{s}$ ) and the gray line is the equivalent latitude of the vortex edge derived from the Nash criterion. A strong dilution of the vortex air after the final warming around October 25 at $\theta=800$ suggests a complete decay of the vortex.

Fig. 5: Contribution of only "weakly mixed" APs (i.e. with the percentage of the pure vortex air higher than $75 \%$ ) relative to the total number of APs in a given isentropic layer calculated in the region southward of $30^{\circ} \mathrm{S}$. The gray contours corresponding to $8 \%$ (solid) and $1 \%$ (dashed) values, respectively, are used to define the regions with a well-isolated vortex $(>8 \%)$ from the regions with strongly diluted vortex air $(<1 \%)$. For $\theta>700 \mathrm{~K}$ the time period between the vortex split and the contour line $\approx 1 \%$ measures the lifetime of the vortex remnants. Below $\theta=700 \mathrm{~K}$, the high contribution of unmixed vortex air is due to an intact, weakly diluted and long-lived vortex between 400 and $600 \mathrm{~K}$.

Fig. 6: Mean ozone loss in the vortex derived from the difference between the POAM observations and CLaMS simulations. The gray contour line confines the region with a well-isolated vortex (see Fig. 5). In the bottom panel, the column ozone loss between 450 and $550 \mathrm{~K}$ is derived from POAM (black) and HALOE (green) observations.

Fig. 7: $\mathrm{CH}_{4}$ /ozone correlations between 400 and 600 within the vortex derived from POAM observations of ozone (crosses) and CLaMS simulations of passive 
ozone (circles). The $\mathrm{CH}_{4}$ /ozone correlations are derived for 3 time periods: 5-11 October (top), 15-21 October (middle) and 20-30 November (bottom) by using

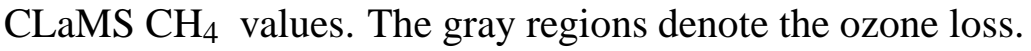



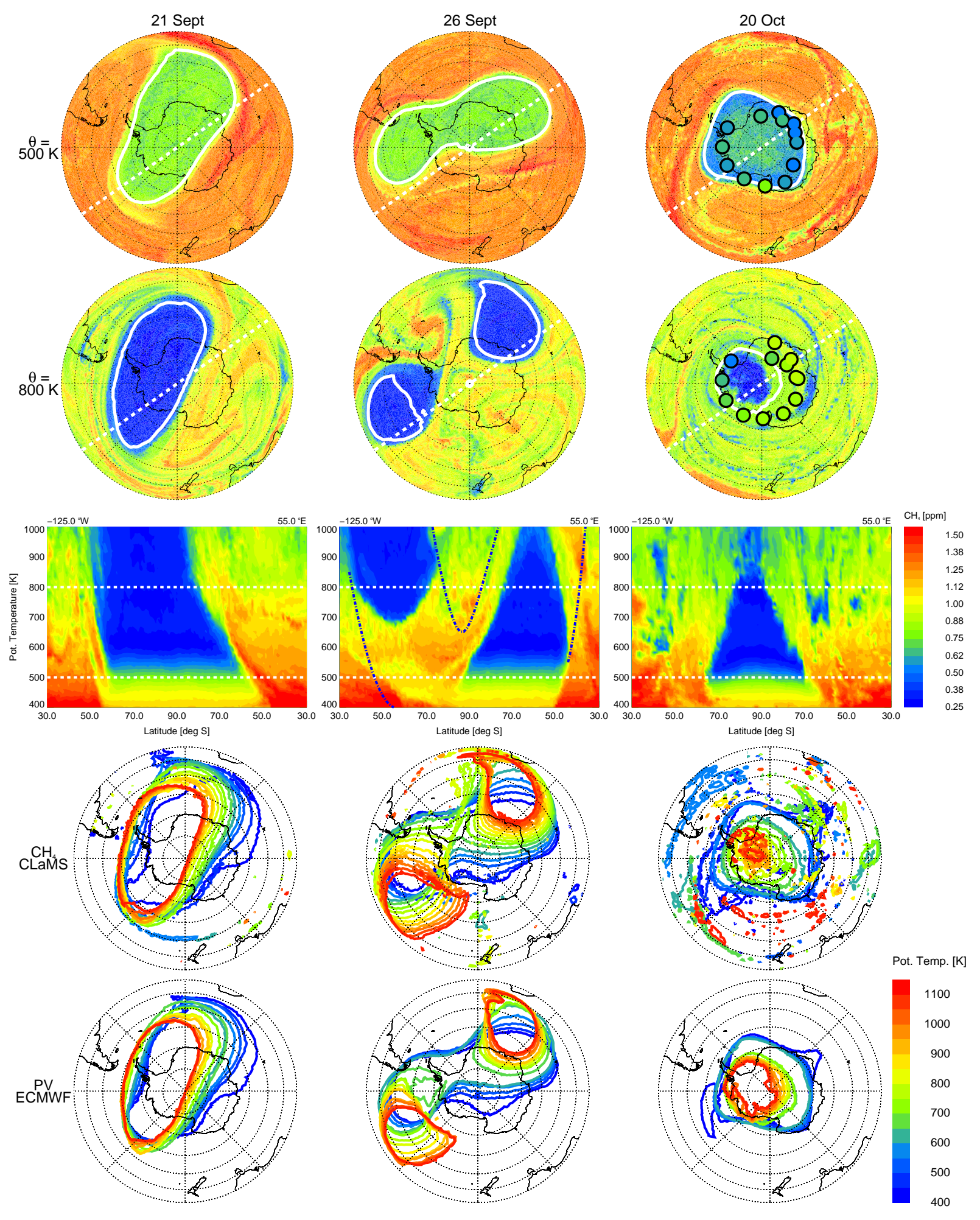

Figure 1: 


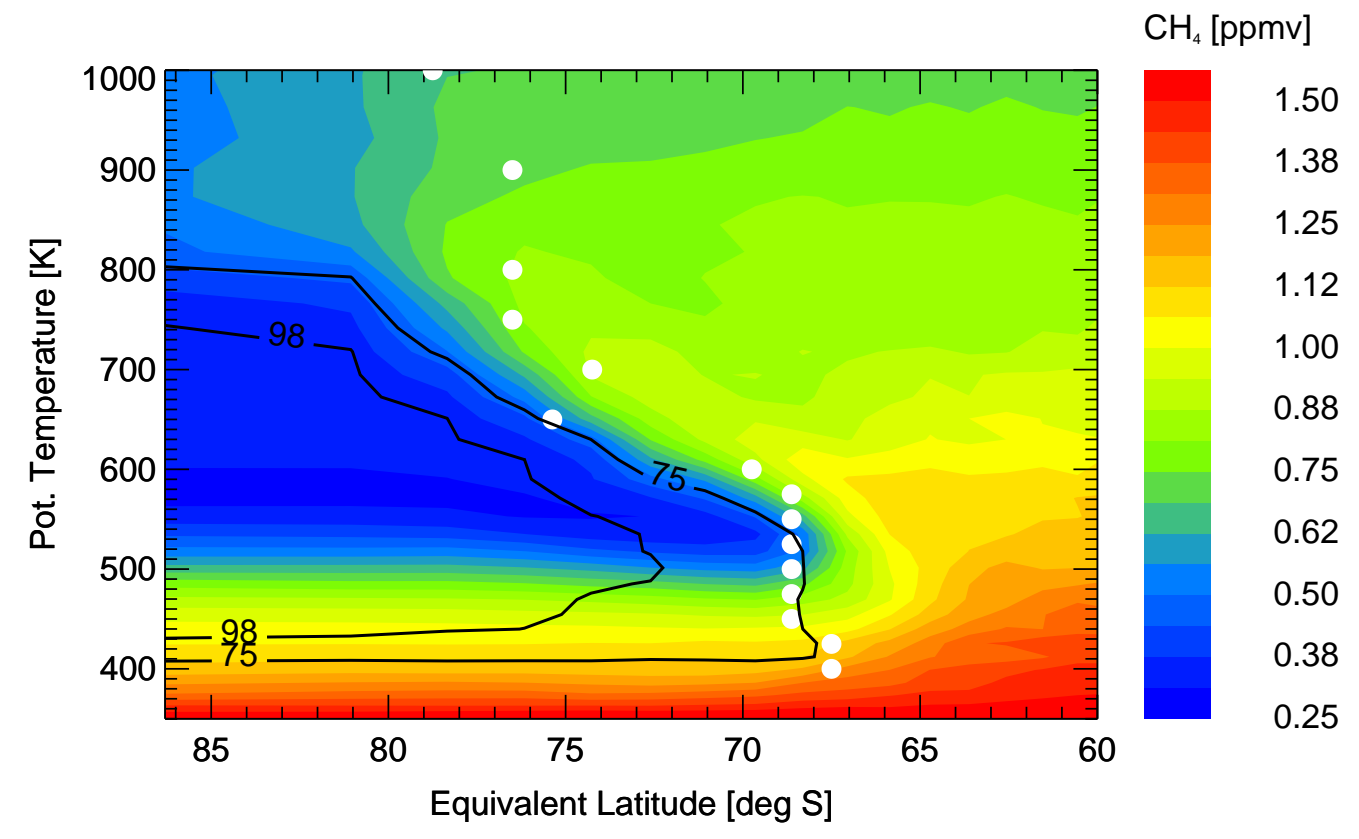

Figure 2: 


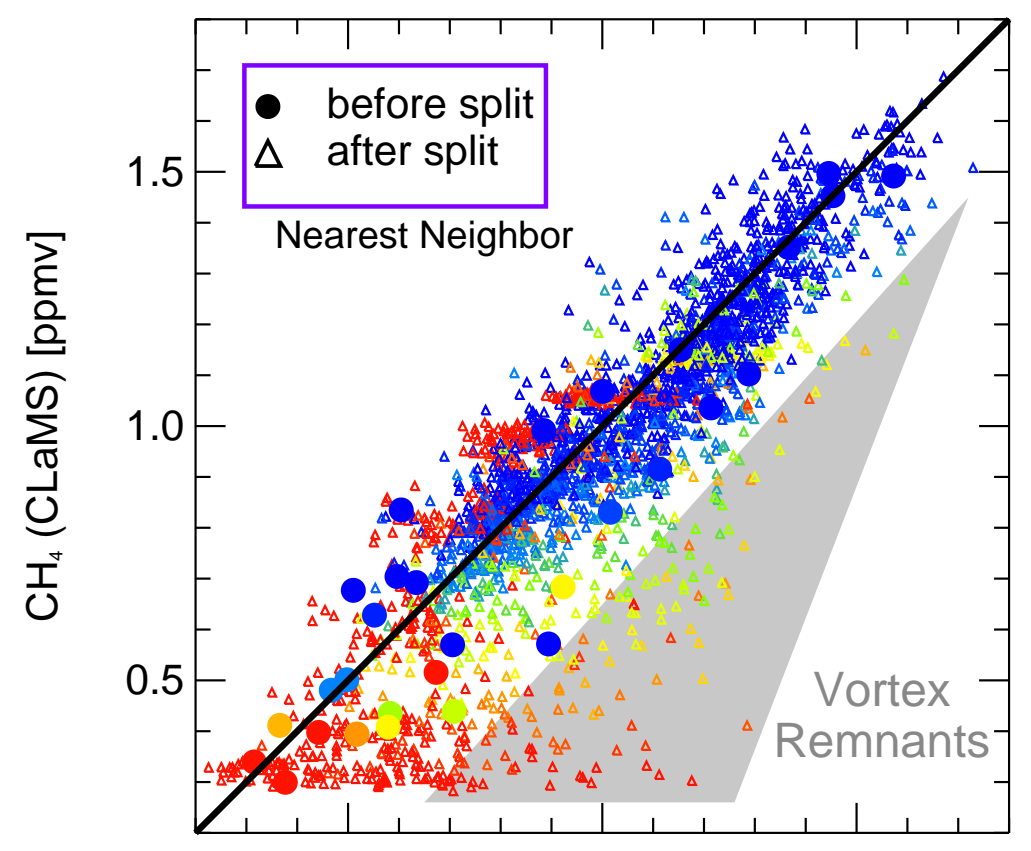

Vortex air [\%]

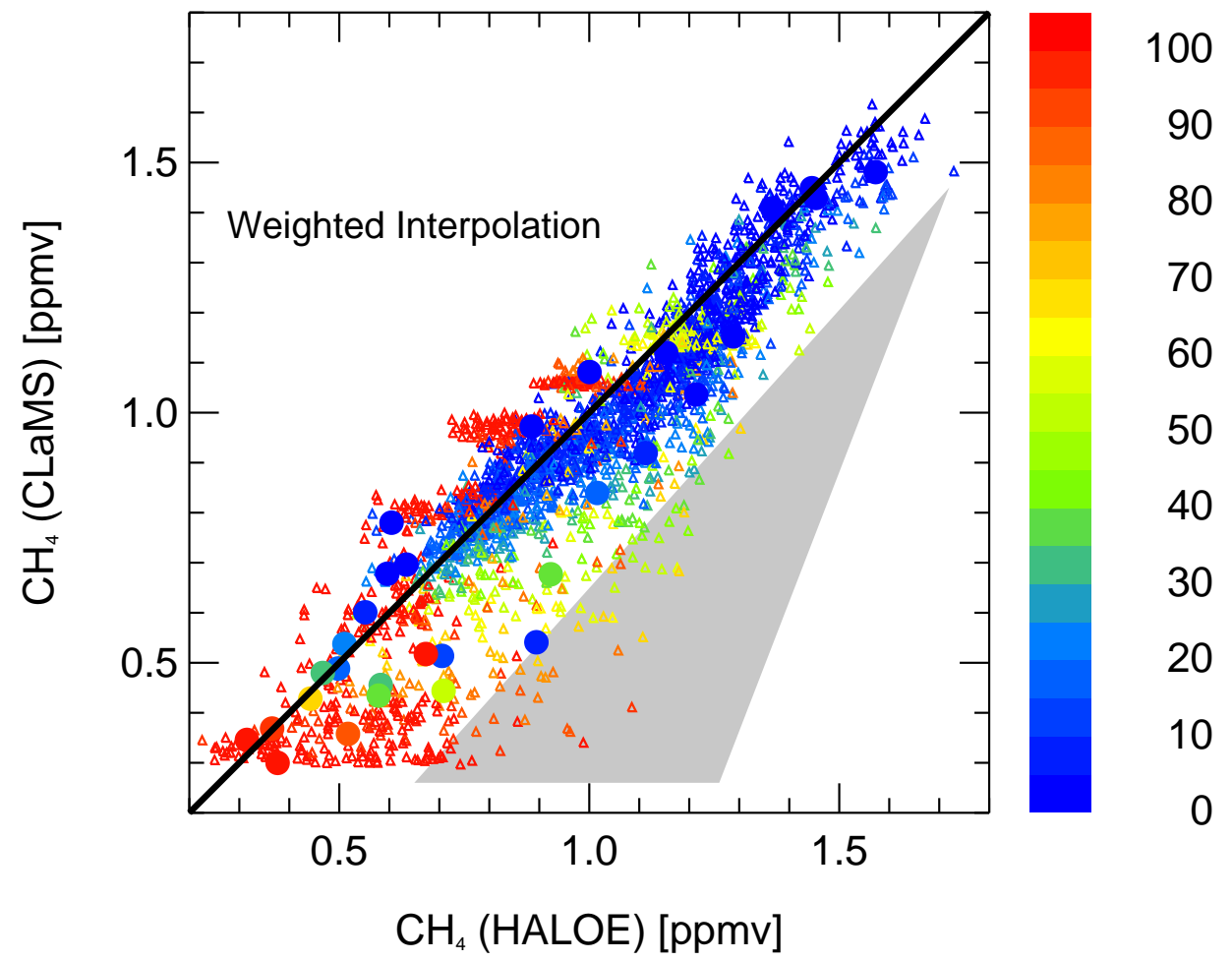

Figure 3: 


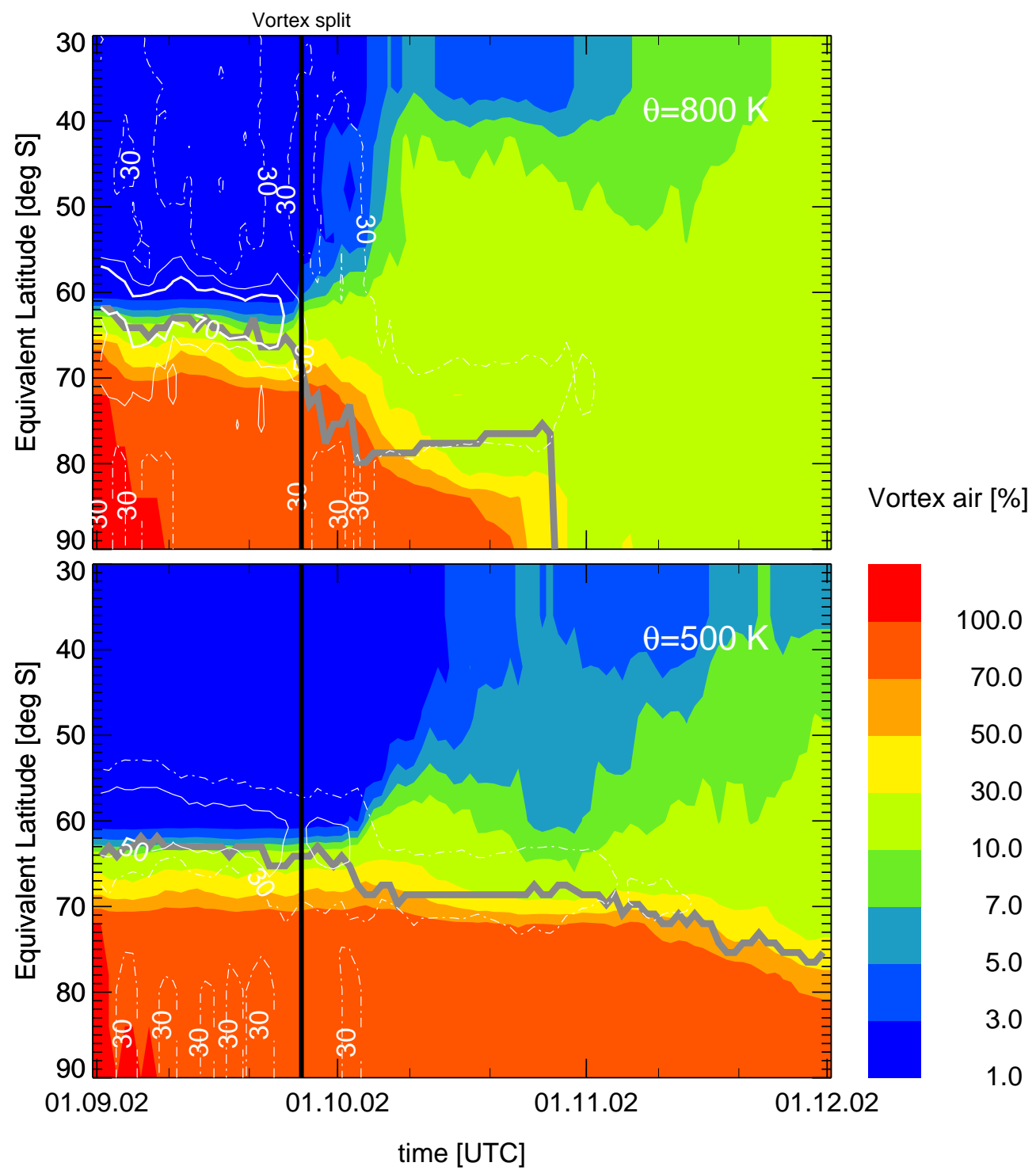

Figure 4: 


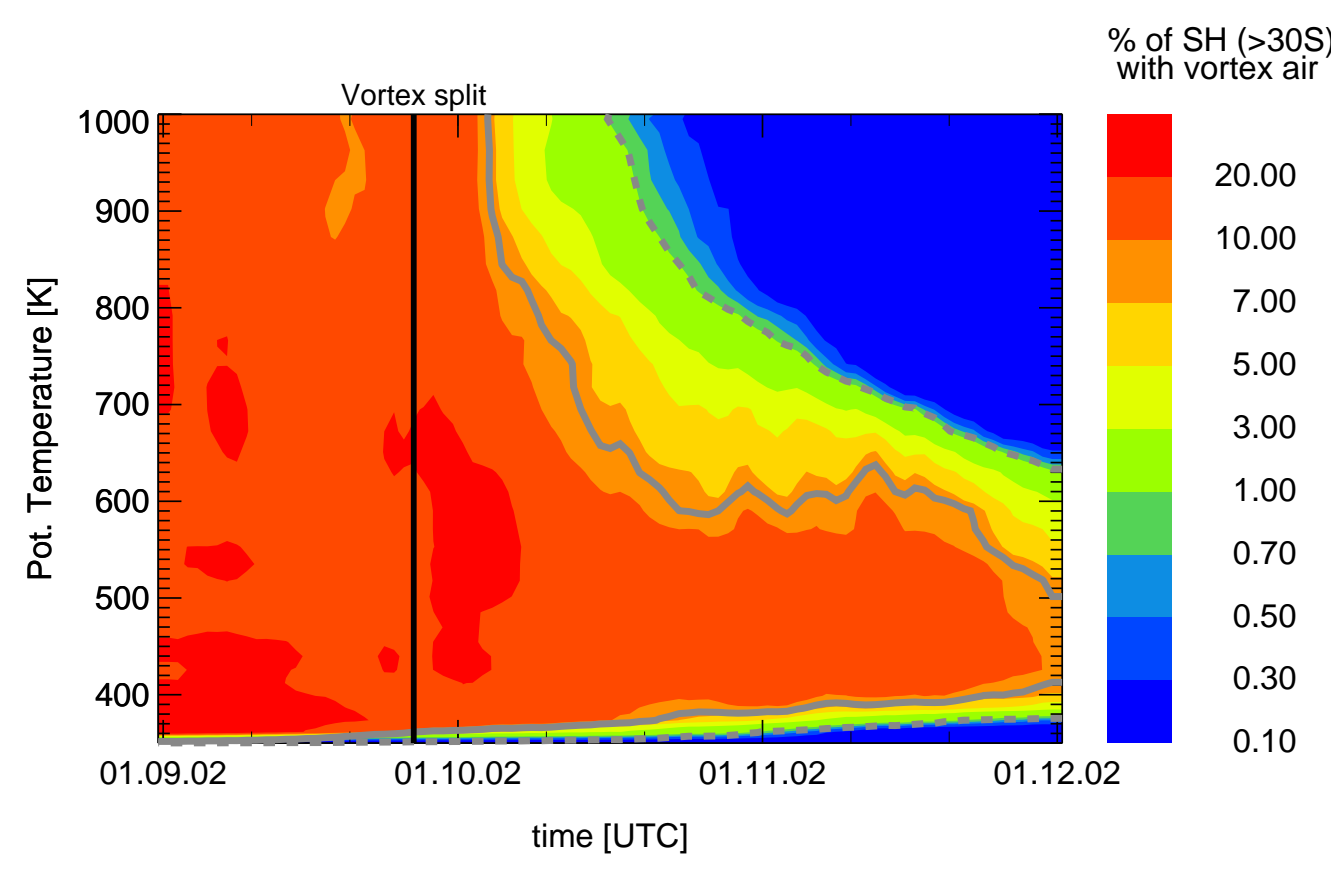

Figure 5: 


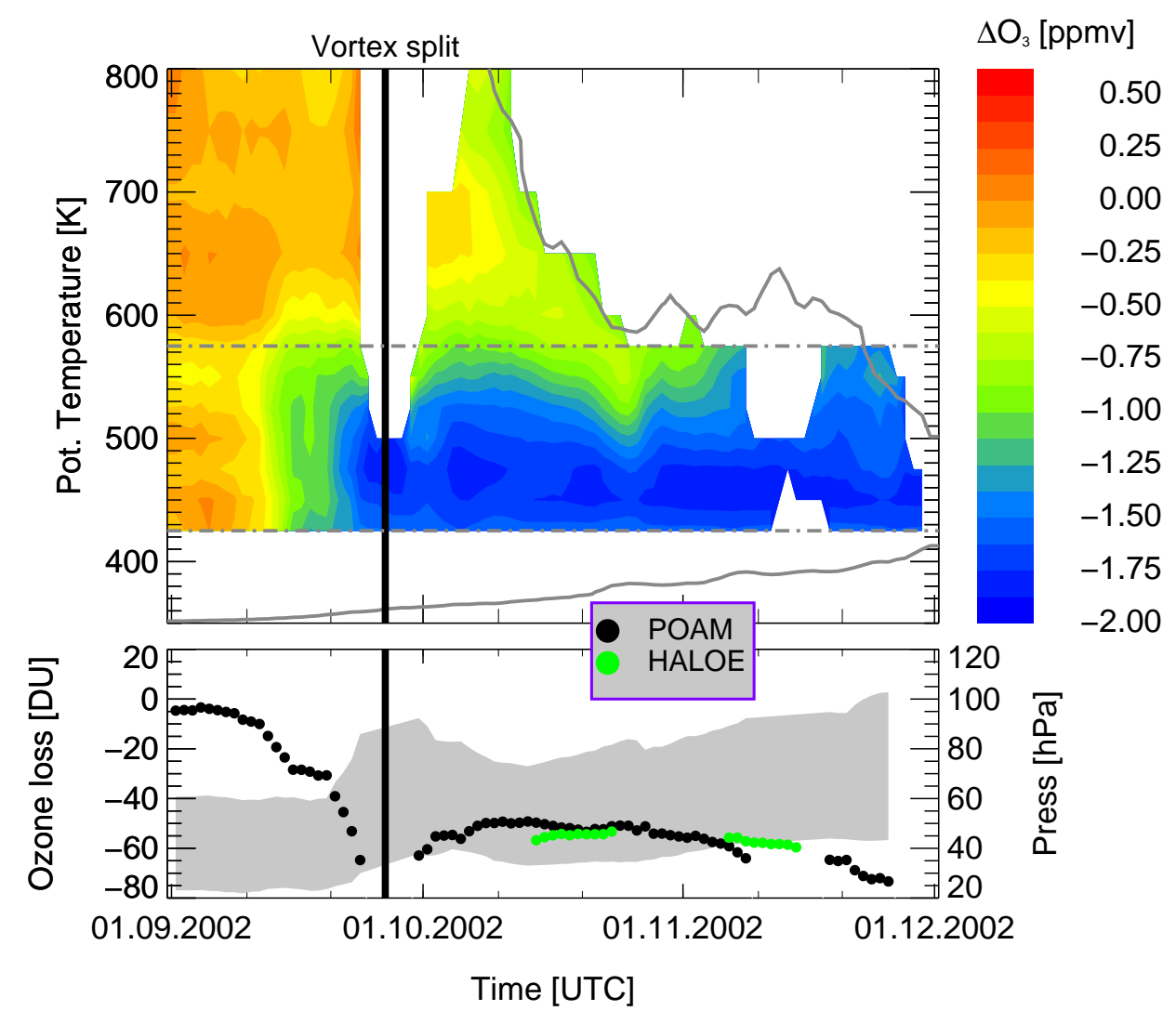

Figure 6: 

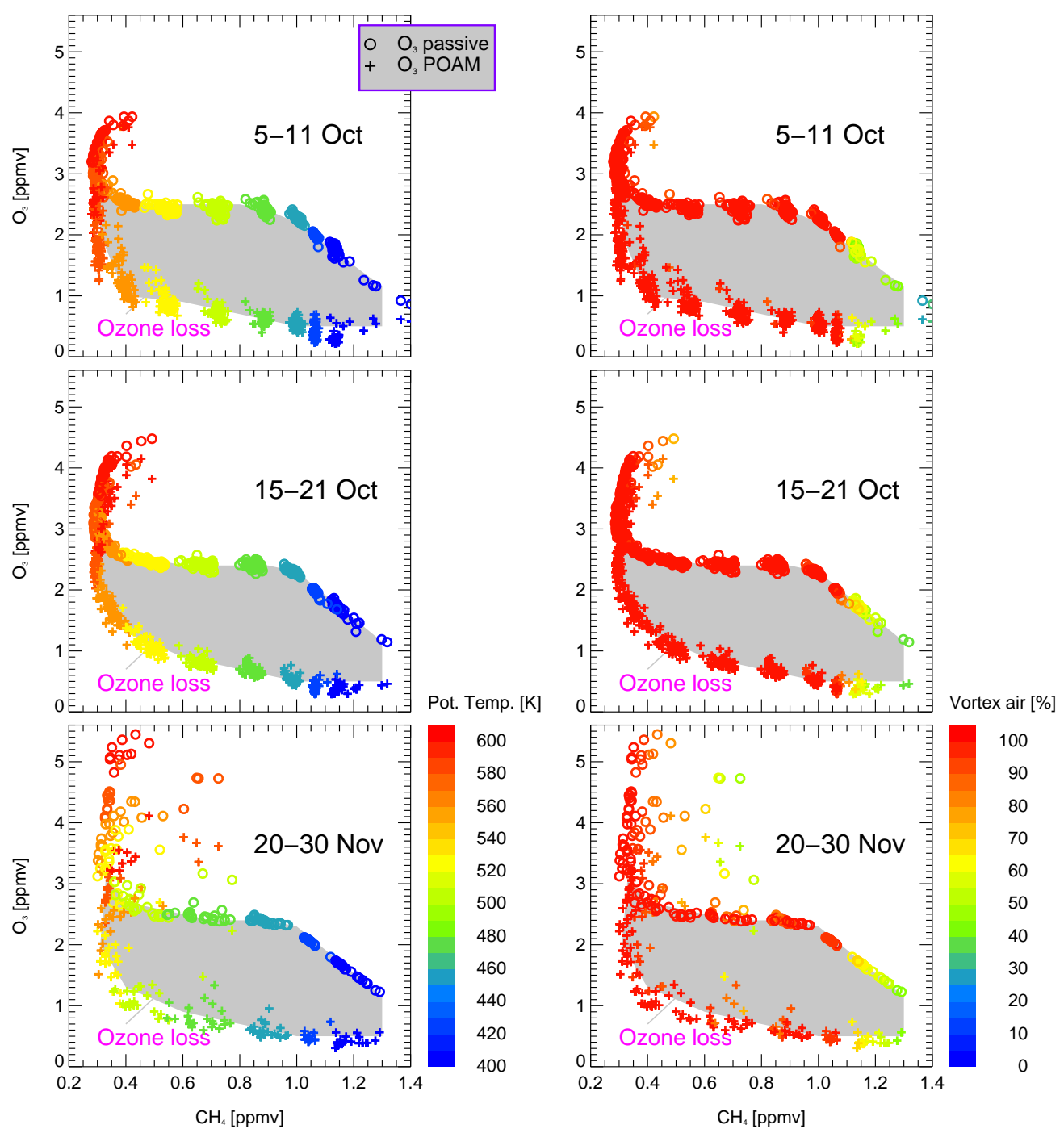

Figure 7: 